soil probes, analysed with methods from modern nuclear physics. The first results of such analyses are still inconclusive, although more measurements, by independent institutes, are under way. So Karlsch can only back his hypothesis with eyewitness reports. Such testimony is notoriously problematic (especially when it is given much later) and is often highly contradictory. As a result, the central argument of Karlsch's book is not all that convincing and is in key parts inconclusive. There is no precise and physically plausible description of the bomb's design, and no reliable analysis of the purported test region to demonstrate that there really was a nuclear reaction.

Even so, Karlsch has written for the most part an interesting, even valuable, book and demonstrates his credentials as a serious historian. The book makes clear that it was well known in the German scientific community that uranium and other nuclear fuels, and even nuclear fusion, could be used to make powerful new weapons. Evidence for this comes from archival material that Karlsch has collected, much of it previously unknown. For example, he discovered a wealth of material in the Russian archives, confiscated from Germany by the Red Army in 1945, including a patent by Carl Friedrich von Weizsäcker (dated summer 1941) for energy production using a uranium pile; this also suggests that plutonium was used as a nuclear fuel.

These documents, and other evidence amassed by Karlsch, demolish the widespread myth that Germany had no chance of building an atomic bomb during the war, and that, even if it did, German physicists (notably Werner Heisenberg's group) would have done whatever was necessary to make sure that such a terrible weapon never made it into the hands of the Nazis. On the contrary, Karlsch demonstrates that numerous German scientists and engineers were grappling with the problem of developing nuclear weapons.

Previous research has focused on Heisenberg and his team, but Karlsch has shifted the focus to other groups. For instance, he shows that Kurt Diebner was perhaps the central figure in Germany's attempt to make an atomic bomb. Not only did Diebner have an idea of the proper arrangement of the uranium cubes in the pile, but Karlsch has uncovered circumstantial evidence that the Diebner group had a critical pile, although not for long enough to produce a significant amount of plutonium. Karlsch also shows that other groups were developing ideas for a nuclear weapon.

Another interesting story related for the first time by Karlsch concerns the activities of Walther Gerlach. He became the administrative head of German nuclear research in 1943, but has never previously been thought to have played a central role in the development of an atomic bomb; he is usually seen only as an ally of Heisenberg and his group. In contrast, Karlsch shows (with the help of new archival material and diligent checking of the old) that
Gerlach was one of the driving forces in the development of a nuclear weapon and was a powerful patron of Diebner and his efforts. This could explain why in 1945, while held at Farm Hall near Cambridge, UK, with other leading German nuclear physicists, Gerlach had the air of a defeated general and had a nervous breakdown after the Hiroshima bomb.

Karlsch's central argument - that Germany had developed and tested a nuclear bomb remains more a sensationalist construct than a proven fact. But his book presents a wealth of interesting and valuable information about the attempt in Nazi Germany to develop a nuclear weapon.

Dieter Hoffmann is at the Max Planck Institute for the History of Science, Wilhelmstrasse 44, Berlin 10117, Germany.

\title{
A happy gathering
}

\section{Happiness: Lessons From a New Science by Richard Layard \\ Allen Lane/Penguin: 2005. 320 pp. E17.99/\$25.95 \\ Making Happy People: The Nature of Happiness and its Origins in Childhood by Paul Martin \\ Fourth Estate: 2005.306 pp. $€ 15.99$ \\ Happiness: The Science Behind Your Smile by Daniel Nettle \\ Oxford University Press: 2005. 224 pp. $E 9.99, \$ 21$}

\section{Dylan Evans}

Books about the scientific study of happiness, it seems, are rather like buses: you spend ages waiting for one, and then three come along at once. The same trend is evident in the science itself, as researchers rush to remedy a longstanding deficit. For much of the twentieth century, psychologists paid scant attention to happiness and related notions, but in the past decade it has suddenly become a hot topic. In this respect, psychology seems to be returning to its roots, as happiness was a central concern for many of the field's founding fathers, such as William James and Sigmund Freud.

The three latest books on the subject have several things in common. They are all popular summaries of the field, aimed at the general public, rather than scientific monographs aimed at specialists. They are all well written, accurate and engaging. And they all cover broadly similar ground. For example, they all start by discussing the various different meanings of happiness and the ways in which happiness can be measured. They all go on to discuss the main factors that make people more or less happy, including money, life events, personality and genes. All explore the increasing evidence for the idea that being happy is good for your health. And they all make the point that scientific research often contradicts our commonsense intuitions about how best to obtain happiness.

That said, there are also differences in the general approach. In Happiness: Lessons From a New Science, Richard Layard examines how research can inform social policy, and argues that happiness is a more sensible goal for society than economic growth. In Making Happy People, Paul Martin is more concerned with the implications of the research for parenting and education. Daniel Nettle, in his book Happiness: The Science Behind Your Smile, prefers to stick to the science itself, and is less concerned with its applications to practical contexts; this makes him — rightly, I think — more sceptical of the idea that happiness is the ultimate goal of human life. In their rush to apply the scientific research to practical matters, Layard and Martin both champion a rather crude version

The smiling faces of children in Baghdad suggest that wealth is not directly related to happiness. 


\section{EXHIBITION \\ Apollo in the lab}

Why is Apollo at the bench? This textbook engraving was designed by the nineteenthcentury natural scientist Emil Du Bois-Reymond a founder of electrophysiology. It was based on a photograph he took of his brother (inset).

Du Bois-Reymond was well schooled in the classics and was a member of a new school of scientists, which held that biological tissues were subject to the laws of physics. $\mathrm{He}$ also believed that experimentation has its own aesthetics.

He worked closely with instrument-makers, for example in developing his Multiplikator, a precision galvanometer that could detect the small transient currents in human muscles when flexed. He believed that the researcher must, through athletic training, become an experimenting Apollo, a part of his instrument. He himself worked out in a makeshift gym in his home where he originally had his laboratory. He became the director of the Physiological Institute in Berlin, but he was unhappy at having less day-to-day control of the experimental work carried out there.

An exhibition of the life and work of Du BoisReymond can be seen at the Berlin Museum of Medical History at the Charité Hospital until 2 October.

A.A.

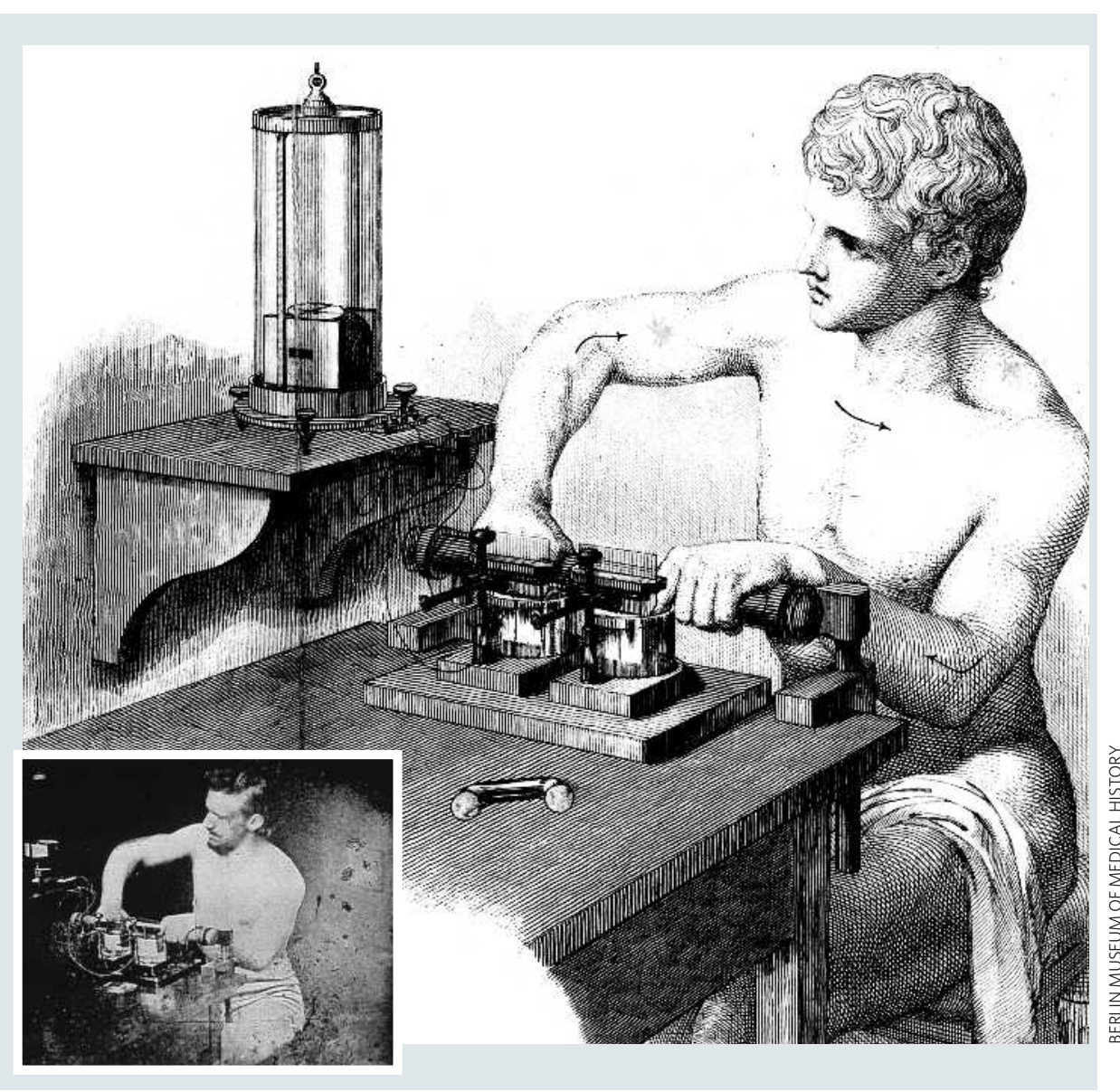

our evolved mind to keep us competing".

Martin is at his best when discussing how the education system so often fails to equip children to lead happy lives, and how it might be changed to remedy this deficit. He makes a powerful case for happiness to feature prominently on the educational agenda, and this is a welcome antidote to the narrow view of education as a preparation for the workplace that is becoming prevalent in many Western countries. His book should be required reading for anyone working in education policy.

None of these three authors can resist the temptation to offer practical tips on how to be happy. But it is a great relief that they all avoid the more messianic tones that have blighted some of the offerings of the 'positive psychology' movement launched by the psychologist-turned-guru Martin Seligman.

If I had to recommend just one of these books, it would be Nettle's, because it conveys about the same amount of information as the other two books in about half the number of words. Yet the conciseness is achieved with a lightness of touch that makes it a delight to read. And Nettle is more aware than Layard and Martin of the paradoxes inherent in the pursuit of happiness - paradoxes that so often make happiness such an elusive goal. Dylan Evans is a senior lecturer in intelligent autonomous systems at the University of the West of England, Frenchay Campus, Coldharbour Lane, Bristol BS16 1QY, UK.

\section{NEW IN PAPERBACK}

\section{Mutants: On Genetic Variety and the Human Body}

by Armand Marie Leroi (Penguin, \$16)

"Mutants is an exquisitely life-enhancing book. It captures what we know of the development of what makes us human, and it recognizes the random tragedy inflicted by nature and nurture." Peter Little Nature 427, 101-102 (2004).

\section{A Brief History of the Human Race by Michael Cook (Granta, £9.99)}

"An elegant, quick and engaging way to review what has happened in history, to learn much that is new, and to appreciate the past of the whole world, not just the West. It meets scientists almost halfway, trying to ground the events of history literally in the material facts of the planet." Melvin Konner Nature 428, 123-124 (2004).

\section{Sight Unseen}

by Melvyn Goodale and David Milner (Oxford University Press, E14.99)

"Goodale and Milner emphasize that much of what goes on in our brains, and even in our cortices, escapes our conscious 'l', partly because of the separation of the visual systems for perception and action... this volume is a perfect present for anyone even remotely interested in the brain." Manfred Fahle Nature 429, 703 (2004). about what will make us happy is, Nettle explains, "a particularly cruel trick played by gone wrong. On the contrary, "the wanting system is supposed to enslave you, to make you maximise your reproductive success". Our tendency to be mistaken in our beliefs 